\title{
Effect of canopy structure and light intensity on seed production in white clover
}

\author{
S.V. PASUMARTY and R.G. THOMAS
}

Botany and Zoology Department, Massey University, Palmerston North

\begin{abstract}
A field experiment was conducted during the summer of 1989-90 to determine to what extent and under what growing conditions the seed yield of white clover flower heads is influenced by canopy density and overcast weather conditions in plants of 'Grasslands Pitau'. Overcast weather was simulated by artificially shading the plants. The flower heads developed in a dense canopy produced $37 \%$ fewer seeds per head than those formed in an open canopy. Seed yield per flower head was also strongly affected by artificial shading. When plants were shaded only before pollination there was a $31 \%$ reduction in seed number per head; when shade was given only after pollination there was a reduction of $25 \%$. It is argued that a major advantage of the practice of defoliation at the time of closing for seed production is enhancement of flower fertility; and that decreased seed set in duller, wetter summers is probably, at- least in- part, attributable to increased ovule sterility in the dense canopies formed under those conditions,
\end{abstract}

K eywords white clover, canopy, light intensity, seed yield

\section{Introduction}

Seed yield in white clover is basically dependent on the number of flower heads per unit area (Zaleski 1961) and adequate pollination of-these by bees (van Bogaert 1977). But even under what seem to be optimum conditions for pollination the number of seeds set per floret is often low. White clover florets most commonly contain 5 or 6 ovules but usually only about one third of these sets seeds (Thomas 1981). The cause of this low seed production per floret is not known despite such knowledge being highly desirable as a basis for the development of improved management practices for seed production.

A possible clue to the cause of this low seed production is the observation that darkness or short photoperiods tend to lead to abortion of developing flower heads (Thomas 1987). Could it be that the low light intensities beneath white clover canopies result in partial abortion of developing flower heads? Brougham (1958) showed that intensities can be as low as $5 \%$ or less of the incoming radiation, and in a dense canopy flower heads spend several days in this environment immediately following their emergence from the apical buds of stolons.

To answer this question, an investigation was begun 2 years ago to test the effect of light intensity on flower head development and fertility under controlled environment conditions. We found that in full light most florets developed fully, but about $20 \%$ of their ovules were sterile. In densely shaded conditions, however, not only did many flower heads abort completely but between 40 and $80 \%$ of ovules in flower heads that did not do so were sterile.

Realising the significance of these observations for seed production practice, a field experiment was conducted in Palmerston North during the summer of 1988-89 using clonal material of 'Grasslands Huia' white clover_to-determine-to-what-extent- and" undēr what growing conditions flower head development and seed yield are influenced by canopy density and overcast weather conditions in plants of Huia. The flower heads developed in a dense canopy produced $39 \%$ fewer seeds per head than those formed in an open canopy. Seed yield was also strongly affected by artifically shading the plants before or after pollination. Some of this reduction was brought about by an increase in the number of florets aborting in all treatments, but much of it was caused by low seed set per pod.

To check whether the low seed set per pod in this experiment might have been the result of ovule sterility, the cytoplasmic state of the embryo sacs and the presence or absence of polar, egg, and synergid nuclei was observed in florets collected from flower heads developed in dense canopies, open canopies, and in plants shaded with shade cloth before pollination (open/prefertilisation shade). It was found that even in good growing conditions an average of only $71 \%$ ovules formed in a flower head was fertile and capable of setting seed and that low light intensity, brought about by either high canopy density or artificial shading, increased ovule sterility. 
The flower heads that developed in dense canopies produced only $54 \%$ of normal embryo sacs compared with $71 \%$ in open canopies. Shading of plants before pollination reduced the ovule fertility to $63 \%$. There was a close correlation between the level of embryo sac fertility and the percentage of ovules setting seed: 71 and $67 \%$ respectively in the open canopy, 54 and $49 \%$ in the dense canopy, and 63 and $56.2 \%$ in the prefertilisation shaded open canopy. The treatments had no significant effect on the number of ovules per floret. The close correlation between the percentage of apparently normal embryo sacs and the percentage of ovules setting seeds strongly suggests that reductions in seed set were brought about by an increase in ovule sterility. In this earlier trial, clonal material of Huia was used to minimise genetic variation. To evaluate the effects of plant density and shade in a variable plant population more similar to those grown in practice as seed crops, the present field trial was set up using a genetically variable population of 'Grasslands Pitau' white clover in which growing 'conditions and treatments were similar to those in the earlier experiment.

\section{Materials and methods}

The experiment was carried out at the Pasture and Crop Research Unit, Massey University, using a 2-year-old Pitau white clover crop growing on Tokomaru silt loam. Table 1 shows the prevailing temperature, precipitation, and sunshine hours. Before the start of the experiment, the crop had been grazed with sheep whenever the herbage reached a height of $\mathbf{1 0 - 2 0} \mathrm{cm}$. The last preparatory grazing was completed on 26 August 1989. The experimental area received a spring application of $250 \mathrm{~kg} / \mathrm{hectare}$ of $30 \%$ potassic superphosphate on 9 October 1988.

The trial was laid out in a randomised complete block design and all treatments replicated 6 times. The area per replicate was $2 \mathbf{m}^{\mathbf{2}}$. All the plots, were defoliated on 30 October 1989 using the herbicide paraquat at the rate of $300 \mathrm{~g}$ ai/ha. Four experimental treatments were given:

\section{A. Open Canopy:}

The plots were manually defoliated for a second time

Table 1 Basic weather data for Palmerston North; Mean values for each month over the experiment period 1989-1990.

\begin{tabular}{lcccc}
\hline Month & \multicolumn{2}{c}{$\begin{array}{c}\text { Temperature } \\
\text { in }{ }^{\circ} \mathbf{C}\end{array}$} & \multicolumn{2}{c}{ Rainfall } \\
& Maximum & Sunshine \\
( & (hours) & \\
\hline Aug & 14.2 & $\mathbf{5 . 3}$ & $\mathbf{5 3 . 1}$ & 124.1 \\
Sept & 16.5 & $\mathbf{1 2 . 4}$ & $\mathbf{2 5 . 3}$ & 150.9 \\
Oct & 18.0 & 9.6 & 123.1 & 129.9 \\
Nov & $\mathbf{2 0 . 0}$ & $\mathbf{1 2 . 0}$ & $\mathbf{2 3 . 0}$ & 191.5 \\
Dec & 20.1 & 11.3 & $\mathbf{5 8 . 8}$ & $\mathbf{1 5 7 . 8}$ \\
Jan & $\mathbf{2 3 . 0}$ & $\mathbf{1 3 . 0}$ & $\mathbf{1 0 4 . 2}$ & 200.9 \\
Feb & 24.9 & 15.2 & 17.5 & $\mathbf{2 2 3 . 2}$ \\
\hline
\end{tabular}

on 15 December to leave residual herbage about $3-4$ $\mathrm{cm}$ high.

\section{B. Open canopy with pre-fertilisation shade (Pre.f.Shade):}

The plots were manually defoliated for a second time as in treatment A. Overcast weather conditions were simulated by artificially shading plants with shade cloth from 16 December 1989 to 15 January 1990. These plants received only $45 \%$ of incoming radiation. After removing the shade, about 16 flower heads in which the oldest corollas were just showing white were tagged per replicate.

\section{Dense canopy:}

The plots received no second defoliation treatment.

\section{Open canopy post-fertilisation shade}

\section{(Post.f.Shade):}

The plots were manually defoliated for a second time as in treatment A. On 15 January 1990 about 16 randomly selected flower heads per replicate were tagged just before anthesis. After these had been pollinated (as judged by the degree of reflexion of their florets), they were shaded from 23 January 1990 with shade cloth until 15 February so that they received only $45 \%$ of incoming radiation.

Measurements: On 15 January about 16 flower heads per replicate were tagged for all treatments, and randomly selected flower heads were harvested to count the ovule number per floret.

On 15 February the tagged flower heads were harvested and the following measurements were made:

1. Number of florets per inflorescence: 96 inflorescences were sampled per treatment,

2. Number of seeds per pod: $\mathbf{1 2 0 0}$ pods per treatment were sampled both from apical (600) and basal (600) florets of 96 inflorescences. To count the number of seeds per pod, the pods were placed on Polaroid photographic paper and X-rayed using a Faxitron Hewlett-Packard $\mathrm{X}$-ray machine (25 KVA, 1 min exposure time).

3. Seed weight: Using the bulked samples of seed for each treatment, four weight counts of 100 seeds each were made. The 1000-seed weight "was standardised to $10 \%$ moisture content.

\section{Results}

\section{Number of florets per head}

The flower heads developed in an unshaded open canopy had the highest number of florets per head (Table 2). In dense canopies and in plants which were artificially shaded before pollination, there was a reduction in floret number by $22 \%$. The postfertilisation shade had no significant effect on the number of florets per head.

\section{Number of ovules per floret}

The average ovule number per floret was 5.54 in florets collected from flower heads developed in the 
Table 2 Effect of treatments on seed yield components per head of Grasslands Pitau white clover.

\begin{tabular}{|c|c|c|c|c|c|}
\hline Treatment & Floret no. & $\begin{array}{l}\text { Seed no. per floret } \\
\text { apical basal }\end{array}$ & $\begin{array}{l}\text { Seed no. } \\
\text { per head }\end{array}$ & $\begin{array}{l}1000 \text { Seed } \dagger \\
\text { weight (g) }\end{array}$ & $\mathrm{mg} / \mathrm{head}$ \\
\hline Open canopy & 58 & $\begin{array}{lll}2.67 & 3.74 & 3.21\end{array}$ & 186 & 0.635 & 118.1 \\
\hline Open/pre.f.shade & $46^{*}(21)$ & $2.36 \quad 3.20 * 2.78 *(13)$ & $128(3 \quad 1)$ & $0.597 \quad(6)$ & $76.4(35)$ \\
\hline Dense canopy & $45 *(22)$ & $2.10^{*} 3.15 * 2.63 *(19)$ & $117(37)$ & $0.599(6)$ & $69.5(41)$ \\
\hline Open/post.f.shade & $53(9)$ & $2.27 * 3.05^{*} 2.66^{*}(17)$ & $140(25)$ & $0.577(9)$ & $80.8(32)$ \\
\hline
\end{tabular}

$\%$ of reduction over open canopy are given in parentheses.

* Significantly different at level of $\mathrm{P}=0.05$ (Student t-test).

$+10 \%$ moisture content.

open canopy. Treatments had no significant effect on the number of ovules per floret.

\section{Number of seeds}

The number of seeds per pod was highest in the open canopy and lowest in the dense canopy (Table 2). In the dense canopy the number of seeds per floret was reduced by $18 \%$ in comparison with the open canopy. Prefertilisation shading of open canopy plants reduced the seed number by $13.4 \%$, and postfertilisation shading reduced it by $17.1 \%$. There was a tendency for the apical florets on a head to possess fewer seeds than those developing lower down (basal). Although the total number of seeds per inflorescence was not counted, this can be estimated by multiplying the average seed number per floret by the average floret number per inflorescence. The results of such calculations (Table 2) show that the total number of seeds per head was highest in the open canopy and most heavily reduced in the dense canopy (by 37\%). Artificially shading the plants before or after pollination also reduced the number of seeds per flower head, by 31 and $25 \%$ respectively.

\section{Seed weight}

- - The 1000-seed weight was- -unaffected- -by the treatments (Table 2).

\section{Discussion}

As soil nutrient status, soil moisture and radiant energy were all satisfactory throughout the experiment (Table 1), the results obtained must be a true reflection of the limitation imposed by radiant energy levels on growth-related reproductive functions as a result of variation in canopy density and artificially shading the plants before or after pollination.

Flower heads that developed in a dense canopy produced $37 \%$ fewer seeds per head than those formed in an open canopy. Artificially shading the plants before or after pollination also reduced the number of seeds per flower head, by $31 \%$ and $25 \%$ respectively. This reduction was not brought about by decrease in the number of ovules per carpel; rather, it was brought about as the combined result of an increase in the number of florets aborting and a decrease in seed number per floret in the dense canopy and when the plants were artificially shaded. Until now, in commercial practice, the most significant component of seed yield has been shown to be the number of flower heads produced per unit area per unit time, i.e., flower density (Zaleski 1961), but all components of seed yield must have an effect. Given high head density, the number of florets per head also influences the seed yield (Van Bockstaele \& Rijckaert 1988). Likewise, given both high head density and a large number of florets per head, yield should theoretically be affected by the number of seeds per floret (Thomas 1981).

The main factor determining seed number per pod in white clover, or any other plant, is the number of fertile ovules produced. Provided that the ovules show a high level of fertility, the seed number per pod will be strongly affected by the number of ovules formed and by weather conditions. Treatments had no significant effect on ovule number. Weather data in Table 1 clearly show that weather conditions were ideally suited for pollination. Despite this, in the present experiment only $58 \%$ ovules set seed in open canopies, $47 \%$ in dense canopies, and $50 \%$ in prefertilisation shaded open canopies. The close correlation between the percentage of apparently normal embryo sacs and the percentage of ovules setting seeds in the earlier experiment suggests-that reductions in seed set in the present experiment were almost certainly brought about by an increase in ovule sterility.

Such increased ovule sterility could result from competition either between ovules in a floret or between florets in a flower head as a result of inadequate photosynthate. The increase in the number of florets aborting in the dense canopy also possibly arose as a result of limited availability of photosynthate.

Defoliation before flowering has been reported to enhance flower production and other components of seed yield of white clover. According to Zaleski (1970), flower head initiation is enhanced as a result of more light reaching the stolon level. The results of this and earlier studies suggest that another major advantage of the practice of defoliation at the time of closing for seed production is the enhancement of floret fertility; and that decreased seed yield in duller, wetter summers is probably, at least in part, attributable to increased ovule sterility and floret abortion in the dense canopies formed under these conditions. This must be a major reason for delaying "closure" for seed production when weather conditions favour rapid and lush growth. 


\section{ACKNOWLEDGEMENTS}

J.H. Archer for technical assistance. D.W. Fountain and J.G. Hampton for continuous help throughout the investigation. This research was supported by funding from Massey University and formed part of the research undertaken for a PhD thesis by S.V. Pasumarty at Massey University.

\section{REFERENCES}

Brougham, R.W. 1958. Leaf development in swards of white clover. $N Z$ journal of agricultural research 1 : 707-718.

Thomas, R.G. 1961. The influence of environment on seed production capacity in white clover (Trifolium repens L.). 1. Controlled environment studies. Australian journal of agricultural research 12: 227-238.

Thomas, R.G. 1979. Inflorescence initiation in Trifolium repens $L$. Influence of natural photoperiods and temperatures. NZ journal of botany 17: $287-299$.

Thomas, R.G. 1981. The influence of environment on seed production capacity in white clover (Trifolium repens L.). 2. Responses to the natural environment. NZ journal of agricultural research 24: 359-364.

Thomas, R.G. 1987. Reproductive development. pp. 63-123. In Baker, M.J., Williams, W.M. (Eds). C.A.B. International.

Van Bockstaele, E.J.; Rijckaert, G. 1988. Potential and actual seed yield of white clover varieties. Plant varieties and seeds I: 159-169.

van Bogaert, G. 1977. Factors affecting seed yield in white clover. Euphytica 2: 233-239.

Zaleski, A. 1961. White clover investigations. 1. Effect of seed rates and cutting treatments on flower formation and seed yield. Journal of agricultural science 57: 199-212.

Zaleski, A. 1970. White clover in seed production. pp. 147-155. In Lowe, J. (Ed.), White clover research. O ccasional symposium No. 6, British Grassland Society. 